\title{
TEORIA DAS RESTRIÇÕES E CONTABILIDADE GERENCIAL: INTERLIGANDO CONTABILIDADE A PRODUÇÃO
}

José Augusto Veiga da Costa Marques Doutor pela EAESP/FGV e Professor dos cursos de pós-graduação e graduação da EGN/UFRJ e do IAG/PUC.

Joanilia Neide de Sales Cia Doutoranda na EAESP/FGV, Professora e Consultora de Empresas.

RESUMO: Como instrumento de apoio à contabilidade gerencial, a teoria das restrições significou uma evolução dos métodos de rateio existentes em razão das mudanças ocorridas no ambiente de manufatura. A escolha da combinação de produtos a serem fabricados emprega uma medida até então esquecida pelos contadores: o ganho por unidade do recurso restritivo.

ABSTRACT: As a supporting instrument of management accounting, theory of constraints meant an evolution of allocation procedures due to changes in manufacture plant. The mix of goods to be processed takes a measure that has been forgotten by accountants: the gain by unit of bottleneck output.

PALAVRAS-CHAVE: teoria das restrições, contabilidade gerencial, restrição, avaliação de desempenho.

KEY WORDS: theory of constraints, management accounting, performance evaluation. 


\section{ASPECTOS INTRODUTÓRIOS}

Dentre as mudanças mais importantes surgidas no âmbito das práticas contábeis recentes destacam-se as introduzidas pelos novos instrumentais colocados à disposição da contabilidade gerencial, em especial as metodologias de rateio dos custos de fabricação dos produtos desenvolvidas a partir dos anos 80: o custeio com base em atividades (activity-based costing - ABC) e o critério com base na Contabilidade dos Ganhos (throughput accounting - TOC).

Os métodos clássicos de custeio - por absorção e direto - ainda permanecem como os mais utilizados pelas empresas para fins de evidenciação externa e gerência interna, respectivamente, a despeito de suas limitações cada vez mais evidentes em ambientes econômicos de acentuada competitividade. Da mesma forma, o ambiente de produção também se transformou, o que contribuiu para a mudança na composição relativa dos custos industriais. Não obstante, ambas as metodologias permaneceram até certo ponto estáticas em face da nova realidade.

A partir dos anos 80 , contudo, começaram a proliferar estudos - a maior parte de natureza acadêmica - ressaltando a inadequação dos instrumentos convencionais adotados pela Contabilidade Gerencial e, sobretudo, os efeitos das decisões derivadas destes instrumentais sobre a posição econômica e financeira das empresas.

No chão de fábrica, cada vez mais os engenheiros de produção se distanciavam dos contadores. As informações extraídas da contabilidade não coincidiam com os planejamentos da produção, embora ambas houvessem partido dos mesmos conjuntos básicos de dados. Por exemplo, a elevação do estoque final de produtos acabados ou em processo era considerada um bom indicador para o contador, haja vista aumentar o ativo total da entidade e permitir o pleno atendimento às iminentes requisições (solicitações dos clientes ou das estações de trabalho subsequientes). Ao contrário, o engenheiro percebia aquela elevação como um fator gerador de custos e despesas, ou seja, o ativo cresceria pela capitalização (ativação) de custos, ao passo que as despesas do período seguinte seriam acrescidas pelos encargos adicionais necessários para manutenção e movimentação daqueles excedentes.

\section{EVOLUÇÃO DOS MÉTODOS DE CUSTEIO DE PRODUTOS}

Tornou-se nítida a mudança do paradigma, mas as companhias relutavam em mudar seus sistemas de informação contábeis, notadamente aqueles referentes ao custeio de seus produtos. A atribuição de valores "verdadeiros" aos produtos passou a constituir um dos principais objetivos da Contabilidade, tanto para a divulgação em suas demonstrações financeiras periódicas o montante do estoque final (em agregado no balanço e parcialmente aberto por tipo de estoque em nota explicativa) e do custo dos produtos vendidos (na demonstração de resultados) - quanto como base para decisão sobre o mix ótimo de produtos. A própria margem operacional bruta compunha o elenco das medidas de avaliação de desempenho mais relevantes.

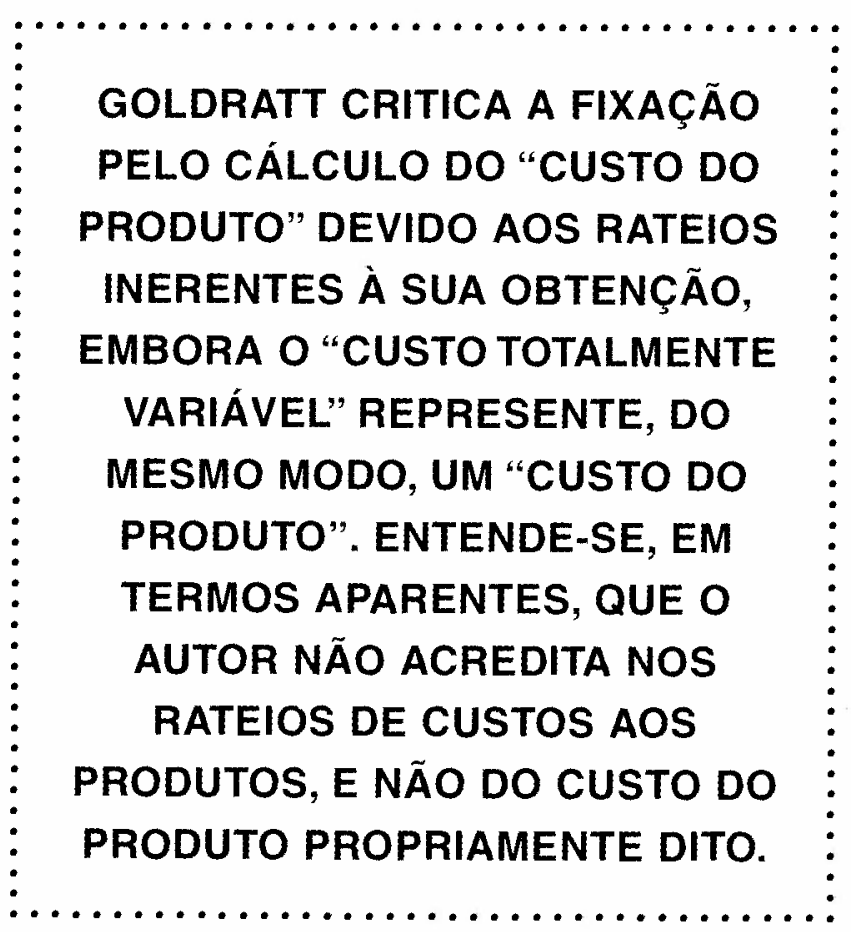

Alguns daqueles estudos, em adição, disseminaram novas metodologias de custeio tidas como mais apropriadas ao ambiente industrial moderno - com predomínio, nos países de origem, da manufatura sincronizada e de alto grau de automação e informatização. As práticas de economias de escala produção no nível máximo de capacidade de modo a minimizar o custo unitário do insumo 
- foram alinhadas às economias de escopo a mesma máquina desempenhando várias funções simultaneamente. Foi neste contexto que a abordagem do custeio por atividades $(A B C)$ se desenvolveu.

O ABC parte da premissa de que produtos consomem atividades, e estas consomem recursos. Assim, as atividades surgem quando determinadas ações direcionadoras de custos acontecem, com o sacrifício de recursos. Por exemplo, diversas ações ocorrem diariamente nas empresas, que consomem

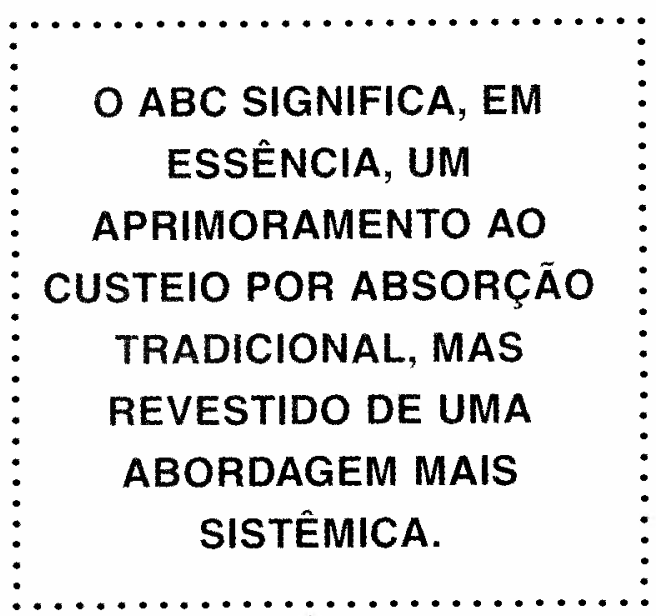

recursos na execução do trabalho dos empregados, expedição de produtos aos clientes, requisições de materiais nas linhas de montagem etc. No rateio, os custos totais inerentes a cada atividade são distribuídos aos produtos de acordo com o número de vezes que foram desempenhadas em suas fabricações. Em outras palavras, o custo indireto de fabricação (CIF) associado a cada atividade seria distribuído aos produtos proporcionalmente ao número de vezes que este a requereu. O custo do produto resultaria do somatório dos CIFs proporcionais consumidos pelas atividades. Na prática, todavia, apenas aquelas atividades mais dispendiosas seriam rastreadas e valoradas para determinação dos custos dos produtos.

O ABC significa, em essência, um aprimoramento ao custeio por absorção tradicional, mas revestido de uma abordagem mais sistêmica. Técnicas como JIT (Just in Time) e TQM (Total Quality Management) foram incorporadas à abordagem. Não obstante, a preocupação pelo alcance do custo "verdadeiro" do produto permaneceu. Essa fixação levou muitas empresas a abandonarem linhas de produtos de pequeno volume que demandavam substancial consumo de atividades, com incentivo à concentração de produtos.

Também em meados de 80 , uma outra abordagem passou a ser difundida em periódicos de renomada tradição como, entre outros, Management Accounting. A exemplo da anterior, esta abordagem pode ser entendida como um aprimoramento em face do novo ambiente e do custeio direto convencional: o custeio com base na teoria das restrições.

\section{A TEORIA DAS RESTRIÇÕES}

A abordagem metodológica criada pela teoria das restrições (theory of constraints TOC) foi inicialmente introduzida por meio da publicação do livro The goal, em 1985, de autoria do físico israelense Eliahu M. Goldratt, traduzido em diversos países. ${ }^{1}$ Escrito sob a forma de romance, o livro descreve as experiências do autor (personificado pelo protagonista Jonah) na elaboração de métodos de otimização de processos industriais, em especial pelo emprego do programa Optimum Production Technology (OPT) - uma aplicação metodológica de Pesquisa Operacional - desde $1980 .{ }^{2}$ A partir dessa publicação, a abordagem expandiu-se para outras áreas da empresa, inclusive pela adição de novos instrumentais à contabilidade gerencial.

Embora recente, a teoria das restrições pode ser dividida em três campos distintos:

1. Um conjunto de ferramentas destinadas à solução de problemas gerenciais: estes instrumentos são denominados Processos de Raciocínio da TOC (Thinking Processes TP) e são empregados de modo a responder lógica e sistematicamente às três questões essenciais de qualquer processo de melhoria de resultados: "o que mudar", "para o que mudar" e "como causar a mudança".

2. Um subconjunto de ferramentas de gerenciamento do dia-a-dia, extraídos dos Processos de Raciocínio, usados para aperfeiçoar as habilidades gerenciais em pontos vitais como, por exemplo, comunicação (negociação, viabilização de idéias), realização de mudanças (resolvendo conflitos crônicos), empowerment (delegando efetivamente) e formação de equipes (para atingir objetivos).

3. Soluções inovadoras criadas a partir da aplicação dos processos de raciocínio TOC em áreas específicas, como produção (con- 
forme discutido no livro citado), distribuição, marketing e vendas, gerência de projetos e planejamento estratégico.

A partir da adoção de conceitos simples e usuais, a TOC estabeleceu uma integração mais efetiva entre as áreas de Contabilidade e Produção, o que acabou por viabilizar a tomada de decisões mais eficazes, sempre com vistas a atingir o objetivo primário de qualquer negócio: ganhar dinheiro agora e sempre - a meta.

O conceito-chave da TOC refere-se à "restrição", ou seja, o fator que restringe a atuação do sistema como um todo. Em essência, restrição significa qualquer obstáculo que limita o melhor desempenho do sistema em direção à meta. Dois tipos de restrições podem ser identificadas: (1) físicas, associadas ao fornecimento de materiais, à capacidade produtiva, à logística e ao mercado; e (2) não-físicas, ou políticas, ligadas a aspectos gerenciais e comportamentais, por meio das normas, procedimentos e práticas usuais.

Em condições usuais, as restrições físicas são de mais fácil detecção, sendo conhecidas como "gargalos" (bottleneck) quando relacionadas à capacidade instalada de fabricação.

Por exemplo, suponha que, numa determinada empresa de vestuário, existam três recursos de produção (máquinas ou operários), dispostos de acordo com o fluxo de produção mostrado na Figura 1.

$\mathrm{Na}$ hipótese de o mercado consumidor absorver quaisquer quantidades de peças de tecido fabricadas, o "recurso restritivo de capacidade" consiste no recurso B. Nesse sentido, caso a firma produza uma quantidade acima de 40 peças ao mês, o efeito desta decisão será a formação de estoques intermediários, mas não maiores vendas efetivas do período. Tais estoques elevarão o total do ativo (investimento) da entidade, sem acar- retar em ganho imediato de dinheiro pelas vendas. A taxa de retorno contábil irá cair, além de aumentarem as despesas com armazenagem e manuseio de materiais. Por outro lado, caso a organização opte por manufaturar somente 40 peças ao mês, o mercado absorverá esse volume sem reflexos no acréscimo de despesas, mesmo às custas de manter dado nível de ociosidade nos recursos $\mathrm{A}$ e C. Em tal situação, a taxa de retorno do mês será mais favorável.

A abordagem TOC recomenda que as restrições físicas sejam gerenciadas de acordo com o seguinte processo decisório:

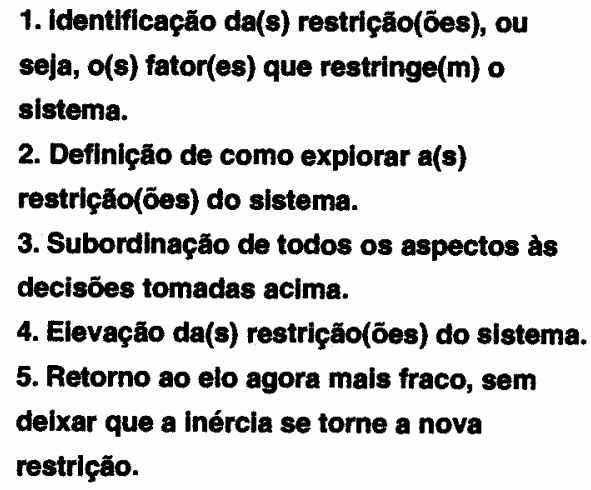

No exemplo exposto, o fator que restringe o desempenho do sistema como um todo é a máquina $\mathrm{B}$ (ou operário $\mathrm{B}$, da costura). Identificada a restrição, a empresa deve inicialmente procurar aproveitá-la da melhor forma possível, com ações do tipo: não permitir que se costurem peças com defeito de corte; evitar que o recurso fique parado à espera de peças ou por outro motivo, como nos intervalos de almoço; ou, ainda, trabalhar apenas com as peças que precisem ser vendidas. A seguir deve-se subordinar os recursos de não-restrição (A-corte e C-embalagem) ao ritmo da restrição (B-costura),

Flgura 1 - Fluxo de produçáo

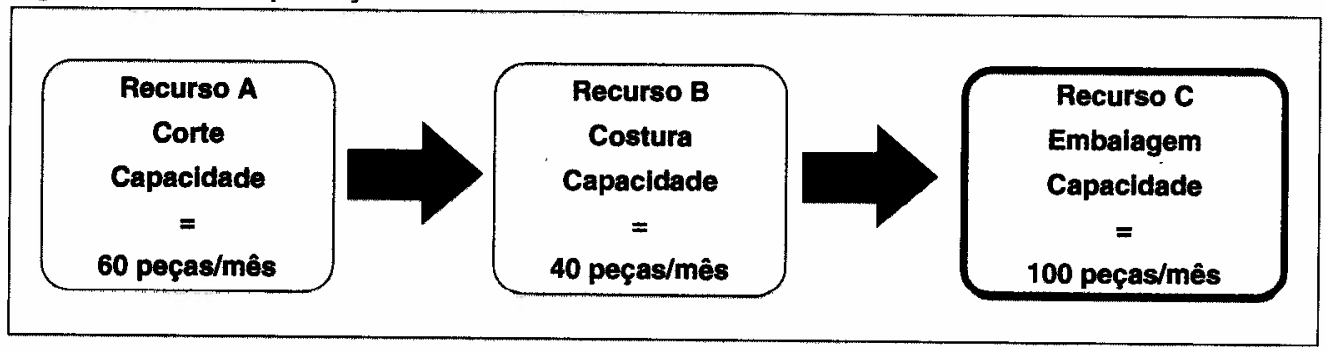

$R A E \cdot$ v. 38 - n. 3 - Jul./Set. 1998 
fornecendo apenas o suficiente para não provocar paradas na costura (recurso $B$ ).

Controlada a situação, a firma pode aumentar a capacidade física, adquirindo outra máquina ou modificando-a de modo a aumentar seu nível de atividade. Após a implementação da primeira decisão, o nível de atividade global crescerá até que alguma melhoria na restrição não reflita em aumento das vendas. Isto significa que uma outra máquina e/ou operário, ou ainda o mercado, torna-se a nova restrição, devendo o processo ser reiniciado.

Ainda com base no exemplo sugerido, algumas constatações parecem evidentes e comuns ao cotidiano das empresas:

1. Equilibrar o fluxo de produção, e não a capacidade de produção. $O$ fluxo sincronizado de 40 peças ao mês não favoreceu a formação de estoques. Após a quebra da restrição, o novo patamar de atividade ficaria mais alto.

2. O nível de utilização de um recurso nãogargalo não é determinado por seu próprio potencial, mas por qualquer outra restrição do sistema. O nível de capacidade do recurso B determinou o nível global do sistema, ainda que os recursos $\mathrm{A}$ e $\mathrm{C}$ permanecessem ociosos.

3. A utilização e a ativação de um recurso não são sinônimos. A utilização dos recursos A e C correspondem a 40 peças semanais, ao passo que suas "ativações" potenciais poderiam superar aquele nível de atividade determinado pela restrição $B$.

4. Uma hora perdida num gargalo representa uma hora perdida para todo o sistema. $\mathrm{Na}$ hipótese do recurso $\mathrm{B}$ deixar de funcionar por um dia, em termos proporcionais, duas peças (40 peças dividido por 20 dias úteis) deixariam de ser fabricadas por dia, elevando a ociosidade dos outros recursos e reduzindo o nível máximo de produção para 38 peças (redução do ganho).

5. Uma hora economizada em um recurso não-gargalo é apenas uma miragem. Economizar o tempo de operação dos recursos A e C é irrelevante, uma vez que ambos estão ociosos. A ociosidade destes recursos pode contribuir para uma diminuição parcial das despesas operacionais, mas não afeta o ganho do sistema.

6. Os gargalos governam o fluxo de produção e o nível dos estoques. Caso a empresa restrinja o nível de produção do sistema ao do recurso $B$, não surgirão estoques de produtos em processo. Não há, pois, incentivo à formação de estoques.
7. O lote de transferência pode não ser, e muitas vezes não deve ser, igual ao lote processado. Em atividades industriais mais complexas, o tamanho do lote a ser completamente processado por um recurso antes que este seja reconfigurado de modo a fabricar outro tipo de produto pode não coincidir com o tamanho do lote a ser transferido de um recurso para outro, e deste para o seguinte, dentro da linha. Essa flexibilidade poderia, segundo a abordagem TOC, diminuir o ciclo de fabricação e o nível médio dos estoques intermediários.

8. O lote processado deve ser variável, e não fixo. Uma vez que cada recurso realiza uma ou mais operações industriais, possivelmente suas características individuais (tamanho do lote de processamento) se diferenciam. Logo, o lote manufaturado por cada recurso deveria ser variável em relação a outro, inibindo a formação de estoques.

9. Os planos de controle da produção devem ser estabelecidos pela percepção de todas as restrições simultaneamente. O tempo despendido na produção é o resultado de um quadro e não pode ser predeterminado. $O$ planejamento da produção requer, nesta abordagem, a observação da(s) restrição(ões) existente(s) dentro e fora da linha de fabricação de modo a se evitar atrasos nas requisições de material, em especial junto ao(s) recurso(s) restritivo(s).

Embora empiricamente simples e lógicas, tais constatações camuflam um conflito clássico entre dois mundos existentes no interior das organizações: o mundo dos ganhos e o mundo dos custos.

\section{O MUNDO DOS GANHOS (TOC) E O MUNDO DOS CUSTOS (ABC E ABSORÇÃO)}

Uma vez visualizados os efeitos das restrições sobre o desempenho do negócio, a TOC estabeleceu uma comparação entre o mundo dos custos - a visão convencional do processo de tomada de decisões pela Contabilidade - e o mundo dos ganhos - a nova abordagem, que enfatiza os ganhos - ao empregar de maneira didática a analogia da corrente.

Em condições habituais, o objetivo de qualquer corrente diz respeito à sua capacidade de transmitir esforço sem se partir. No mundo dos custos, a principal medida de avaliação de desempenho consiste no custo-padrão e na análise das variâncias, o que significa que as deci- 
sões para alcance da meta visam a redução dos custos, que, na analogia, corresponderia à redução de peso da corrente. Controlar os padrões de custos de fabricação no intuito de diminuir o custo total equivale à diminuição do peso da corrente via redução do peso de algum elo independente. As características desta abordagem seriam assim resumidas: de análise de eficiências ou disfunções no emprego dos recursos. Em adição, a ênfase pela otimização dos insumos resulta em maiores níveis médios relativos de estoque, bem como das despesas adicionais na sua movimentação, manutenção e manuseio, além do acréscimo às perdas (defeitos, quebras e obsolescência). Por conseguinte, parte-se do pressuposto de que a eliminação da ociosidade de qualquer recurso contribuiria para a elevação do ganho global da entidade, o que, em verdade, somente ocorreria se este representasse o fator restritivo.

$\mathrm{Na}$ visão do mundo dos ganhos, apenas a máxima utilização do recurso restritivo de

Segundo ficou evidenciado no exemplo, entretanto, o controle dos custos inerentes aos recursos A e C não se traduziu em melhoria efetiva no ganho do negócio. Aumentar a capacidade de fabricação destes recursos não resultaria em acréscimo às vendas, mas sim em maiores estoques de produtos em processo. A melhoria global somente seria conseguida se o recurso B manufaturasse mais de $\mathbf{4 0}$ peças ao mês.

Do lado inverso, no mundo dos ganhos, a entidade compõe-se de sub-sistemas, os elos, ao passo que as decisões visam ao aumento da resistência da corrente, e não à redução de seu peso. Logo, somente o fortalecimento de seu elo mais fraco determinaria a resistência do sistema no intuito de maximizar a capacidade da corrente na transmissão de esforço. Em outras palavras:

capacidade (gargalo) determinaria o desempenho global do negócio. Ao se manter a máxima eficiência neste recurso - mesmo em detrimento de níveis de ociosidade nos demais -, a receita permaneceria estabilizada, mas a diminuição relativa dos custos e despesas poderia ser expressiva, elevando o resultado global.

\section{MEDIDAS CONTÁBEIS DE DESEMPENHO NA TOC}

A abordagem TOC apresenta outra analogia com a finalidade de associar a meta da empresa às medidas de desempenho disponíveis. Nesse sentido, supondo-se que a organização deseje adquirir uma "máquina de fazer dinheiro", com certeza a decisão seria por aquela que produzisse o maior volume de recursos (lucro líquido) em proporção ao capital despendido (investimento). Esta decisão de lucratividade se fundamenta em três conceitos, como mostra a Figura 2:

1. Ganho (throughput): diz respeito ao dinheiro gerado pelo sistema durante o período. Em condições normais, a receita operacional líquida se converte em disponível em prazo relati-

Em verdade, na visão tradicional buscase a máxima eficiência na utilização dos fatores de produção - economias de escala -, reduzindo ao máximo seu custo por unidade de produto. A diferença entre valores reais e padrões preestabelecidos representa objeto vamente curto, assim como expressiva parcela das encargos variáveis o consome. $\mathrm{O}$ ganho deriva-se da diferença entre a receita líquida e os "custos totalmente variáveis".

2. Despesas operacionais: correspondem aos custos e despesas incorridos no proces- 
Figura 2 - Medidas contábeis da TOC

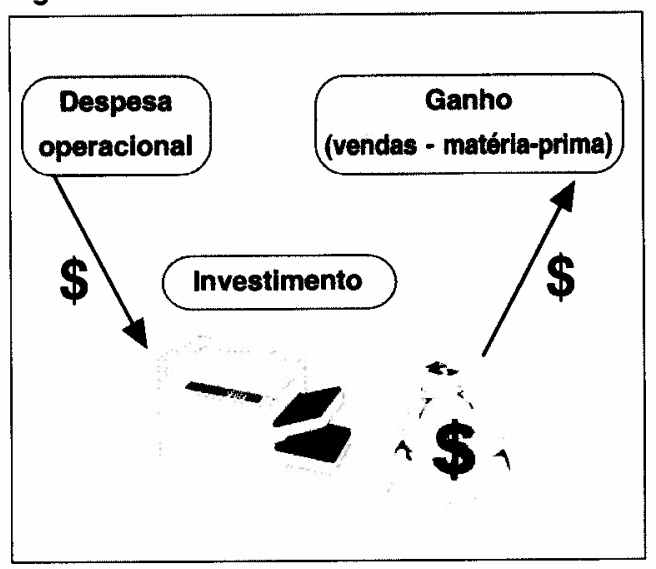

so de transformação de matérias-primas em produtos acabados que não sejam "totalmente variáveis".

3. Investimento (ativo): recursos que, em algum período, serão empregados no esforço de gerar receita. Numa avaliação conservadora, poderia significar o montante do ativo operacional médio.

O emprego das medidas contábeis na abordagem TOC pode ocorrer com pequenas modificações, dependendo do segmento de negócio envolvido. Em estudo sobre a implementação da abordagem TOC em empresas industriais européias e norte-americanas, Noreen, Smith \& MacKey constataram que:

"A definição oficial corrente de ganho é receitas menos 'custos totalmente variaveis. Contudo, na maior parte da literatura TOC, ganho tem sido conceituado como receitas menos o custo do material direto. Na prática, observamos ambas as versões em uso. Algumas empresas deduzem apenas o custo do material direto das receitas de modo a chegar ao ganho, enquanto outras deduzem outros custos variáveis como mão-de-obra subcontratada, despesas variáveis de vendas e custos variáveis de expedição. A versão mais simples pode ser utilizada haja vista não existirem outros custos variáveis relevantes além do material direto. Suspeitamos, todavia, que alguns gerentes têm empregado a definição mais simples apenas porque é a definição usada na maior parte da literatura TOC. Não aprofundamos essa questão nesta area de investigação.

Ativos (investimento) na Contabilidade dos Ganhos são idênticos aos ativos da con- tabilidade financeira convencional, exceto pelos estoques. Estoques na Contabilidade dos Ganhos, como no custeio direto, abrangem somente os custos totalmente variáveis, os quais também têm sido incluídos no registro dos custos das vendas.

A Despesa Operacional consiste de todas as despesas (e custos) que não são deduzidas na obtenção do ganho. A soma das despesas operacionais e das deduções da receita na determinação do ganho é idêntica à soma das despesas reconhecida na demonstração de resultado sob o custeio por absorção convencional, exceto pelo registro dos custos adicionais capitalizados em estoques sob a contabilidade financeira convencional."3

Em síntese, o ganho na abordagem TOC expressa, na vasta maioria dos casos analisados, a diferença entre a receita operacional líquida e o custo da matéria-prima. Por sua vez, o investimento equivale ao ativo total divulgado para o período menos o CIF fixo rateado no custeio por absorção. Já a despesa operacional inclui todas as despesas e custos fixos ou semifixos. Não obstante, a forma de registro de determinados eventos - como arrendamento mercantil, $P \& D$, treinamento de pessoal, amortização de intangíveis e campanhas de propaganda - poderia alterar de maneira acentuada os montantes do investimento e da despesa operacional, a exemplo da prática cotidiana (legislação societária em oposição aos princípios contábeis).

Por outro lado, os três conceitos derivam as medidas de desempenho abaixo relacionadas:

1. Lucro líquido do período: obtido da diferença entre o ganho e os custos (e as despesas operacionais), significa uma medida absoluta de lucratividade para avaliação do nível de geração de dinheiro pelo sistema;

2. retorno sobre o investimento: resultante da divisão entre o lucro líquido e o investimento empregado; corresponde à medida relativa de lucratividade do modelo;

3. fluxo de caixa: medida absoluta de liquidez; por aproximação, pode ser conseguida pela dedução ao capital de giro das operações da variação positiva líquida dos ativos circulantes (exceto disponível) e inclusão da variação positiva líquida dos passivos circulantes. Representa uma condição necessária à manutenção de níveis adequados às medidas de lucratividade. The theory of constraints and its implications for management accounting. s.l., The North River Press, 1995. p.13. 
Dentro destes princípios, a TOC desenvolveu uma ferramenta de medição, denominada bússola, ${ }^{4}$ que possibilita determinar o impacto financeiro de uma decisão específica. Desta forma, cada pessoa conta com um mecanismo coerente para a tomada de decisão, com o qual é induzido a fazer o que é bom para a organização como um todo, seguindo sempre a direção da meta de ganhar dinheiro hoje e sempre.

\section{A TEORIA DAS RESTRIÇÕES E O CUSTEIO DIRETO}

Como pode ser notado, em muitos aspectos a abordagem TOC se aproxima do custeio direto no tocante às medidas de desempenho. A nova visão representaria, assim, uma metodologia radicalmente inovadora em face das técnicas contábeis hoje conhecidas? Certamente não. A abordagem TOC significa, sim, uma evolução ao método de custeio direto, mas revestida por uma visão sistêmica - à semelhança da evolução do custeio por absorção para o ABC. Na opinião de Noreen, Smith \& MacKey:

"Ao nível conceitual, o ganho não se distingue da margem de contribuição. $O$ ganho consiste da receita menos os 'custos totalmente variáveis', e a definição geral de margem de contribuição é receita menos os custos variáveis. Também ao nível conceitual, não existem diferenças entre a Contabilidade dos Ganhos e o custeio direto. Na prática, porém, existe uma diferença relevante - o tratamento do custo da mão-de-obra direta. Na Contabilidade dos Ganhos o custo da mão-de-obra direta não é deduzido quando computado o ganho e não é capitalizado ao estoque. Ao invés, é incluído como parte das despesas operacionais. O tratamento usual no custeio direto consiste em considerar mão-deobra direta um custo variável. Entretanto, esta é apenas uma convenção e, caso a mão-de-obra direta seja considerada fixa sob o custeio direto, então este custeio seria igual à Contabilidade dos Ganhos, alheio ao modo com que umas poucas contas são trabalhadas."

Em verdade, a inclusão no custeio direto da mão-de-obra direta (MOD) no conjunto dos custos e despesas variáveis tem sido mais uma questão de tradição acadêmica do que de resistência à mudança. Em termos literais, toda a literatura contábil existente associada à análise do custo-volume-lucro e custeio direto incorpora a MOD aos encargos variáveis. Sua adaptação tornaria ambas as metodologias equivalentes, nas medidas gerais de desempenho.

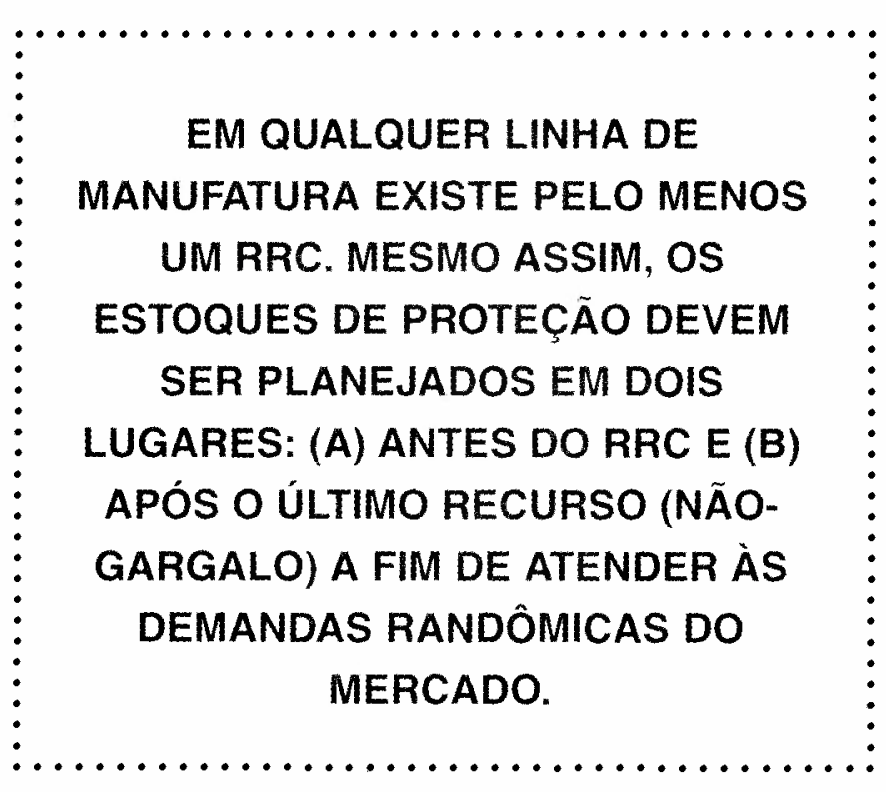

Um aspecto curioso diz respeito à interpretação daqueles autores acerca da postura de Goldratt sobre "custo do produto":

"Como outros críticos das práticas de contabilidade de custos tradicionais, Goldratt acredita que o custeio por absorção usual foi razoavelmente exato nos primórdios da contabilidade de custos, quando o custo da mão-de-obra direta era variável e existia um reduzido overhead. Todavia, mão-de-obra agora é largamente fixa e o overhead tem se tornado uma grande parcela do custo total. Goldratt critica a companhia, assim como aqueles que advogam o custeio por atividades como um meio de restaurar a relevância da contabilidade de custos, por não acreditar que o custeio por atividades pode fornecer respostas confiáveis à questão 'Qual impacto a decisão terá sobre os ganhos, as despesas operacionais $e$ os ativos?'.

De modo a nos livrar do tipo de raciocinio que conduz aos custos dos produtos totalmente distribuidos, Goldratt acredita que se torna necessário expurgar o termo
4. Esta ferramenta é estudada no seminário "Mundo dos Ganhos", ministrado pelo AGI - Instituto Goldratt do Brasil.

5. NOREEN, Eric, SMITH, D., MACKEY, J. T. Op. cit., p.13-4. 
'custo do produto' de nosso vocabulário. Ele está certo de que não existe uma coisa como custo do produto na realidade, embora deduza os 'custos totalmente variáveis' das receitas de maneira a chegar ao ganho para um produto."

Ou seja, Goldratt critica a fixação pelo cálculo do "custo do produto" devido aos rateios inerentes à sua obtenção, embora o "custo totalmente variável" represente, do mesmo modo, um "custo do produto". Entende-se, em termos aparentes, que o autor não acredita nos rateios de custos aos produtos, e não do custo do produto propriamente dito.

O Quadro 1 mostra uma comparação de custeio variável com contabilidade do ganho.

As duas posições - mundo dos custos e dos ganhos - diferem de modo acentuado quanto à ênfase em cada um dos três conceitos citados. No mundo dos custos, enfatizase relativamente mais a redução das despesas operacionais, haja vista serem de mais direto controle da Administração. Em segundo nível ficam as decisões ligadas a ganhos e, por último, aquelas associadas ao investimento empregado.

Em contraste, no mundo dos ganhos, a ênfase maior recai sobre o ganho, em tese considerado de crescimento infinito. Em seguida, as decisões voltam-se para as despesas operacionais, as quais possuem um limite máximo de redução sem que o ganho seja afetado. Por último, permanecem as decisões relacionadas a investimento.

\section{SISTEMA LOGÍSTICO DO TAMBOR- PULMÃO-CORDA}

Goldratt \& Fox desenvolveram um sistema logístico denominado tambor-pulmão-cor$\mathrm{da}$, o qual passou a representar a interligação entre a Contabilidade e a Produção. Tal sistema limita o planejamento do fluxo de produção à restrição física da linha, denominada recurso restritivo de capacidade (RRC):

"Em qualquer fábrica existem uns poucos recursos restritivos de capacidade ( $R R C s)$ os soldados mais fracos. Esta percepção do $R R C$ reconhece que tais restrições decidirão a taxa de produção de toda a fábrica. Assim, permita-nos tratar o principal recurso restritivo como o tambor. Sua taxa de produção servirá como um ritmo para toda a manufatura. Também precisaremos estabelecer um estoque de proteção para cada $R R C$. Esse nivel de segurança será constituído apenas do estoque necessário para manter o $R R C$ ocupado durante o próximo intervalo de tempo predeterminado (iremos nos referir como pulmāo a este tempo de proteção). Em conseqüência, este pulmão produzirá o tempo de processamento da fábrica contra qualquer disfunção que possa ocorrer dentro do intervalo de tempo predeterminado".

De modo a assegurar que aquele estoque não crescerá acima do nível estabelecido pelo pulmão, devemos limitar a taxa na qual a matéria-prima é transformada na manufatura.
Quadro 1 - Comparativo da contabilidade de ganho $X$ custeio variável

\begin{tabular}{|c|c|c|c|}
\hline $\begin{array}{l}\text { Custeio variável } \\
\text { convencional }\end{array}$ & $\begin{array}{l}\text { Custeio variável com mão-de-obra } \\
\text { direta classificada como fixa }\end{array}$ & $\begin{array}{l}\text { Contabilidade } \\
\text { do ganho }\end{array}$ & $\begin{array}{l}\text { Contabilidade do } \\
\text { ganho simplificada }\end{array}$ \\
\hline Receita & Receita & Receita & Receita \\
\hline $\begin{array}{l}\text { (-) Materiais } \\
\text { diretos } \\
\text { (-) Māo-de-obra } \\
\text { direta } \\
\text { (-) Despesas } \\
\text { administrativas* }\end{array}$ & $\begin{array}{l}\text { (-) Materiais } \\
\text { diretos } \\
\text { (-) Despesas } \\
\text { administrativas* }\end{array}$ & $\begin{array}{l}\text { (-) Custos } \\
\text { totalmente } \\
\text { variáveis }\end{array}$ & $\begin{array}{l}\text { (-) Materiais } \\
\text { diretos }\end{array}$ \\
\hline $\begin{array}{l}\text { = Margem de } \\
\text { contribuiçāo } \\
\text { (-) Despesas } \\
\text { fixas }\end{array}$ & $\begin{array}{l}\text { = Margem de } \\
\text { contribuiçāo } \\
\text { (-) Despesas } \\
\text { fixas }\end{array}$ & $\begin{array}{l}\text { = Ganho } \\
\text { (-) Despesa } \\
\text { operacional }\end{array}$ & $\begin{array}{l}\text { = Ganho } \\
\text { (-) Despesa } \\
\text { operacional }\end{array}$ \\
\hline$=$ Lucro & = Lucro & = Lucro & = Lucro \\
\hline
\end{tabular}

*Despesas gerais e administrativas tanto de produção como de não-produçāo. 
Uma corda deveria ser amarrada do RRC à primeira operação. Em outras palavras, a taxa na qual da operação inicial a matéria-prima se transforma em produto acabado seria ditada pela taxa em que o RRC está produzindo.

"Tais conceitos parecem sonoros, assim, permita-nos derivar um procedimento de modo a implementar a abordagem logística do $R R C$, o sistema tambor-pulmão-corda, na fábrica. Um bom sistema logístico deveria possuir os meios (planos e quadros de produção) a fim de controlar o fluxo de materiais dentro, através e fora das indústrias sem relação a quanto complicados possam ser. Este representa justamente o procedimento que necessitamos desenvolver."

Com base neste raciocínio, em qualquer linha de manufatura existe pelo menos um RRC. Mesmo assim, os estoques de proteção devem ser planejados em dois lugares: (a) antes do RRC, segundo explicado pelos autores, e (b) após o último recurso (não-gargalo), a fím de atender às demandas randômicas do mercado.

\section{SIMULAÇÃO: EMPRESA INDUSTRIAL P\&Q}

Como forma de realizar uma análise comparativa sobre os efeitos contábeis das decisões gerenciais obtidas com base nas abordagens convencional e da TOC, o exemplo da firma $P \& Q^{9}$ foi transcrito a seguir:

A empresa industrial $P \& Q$ Ltda. fabrica $e$ vende os produtos $P$ e $Q$. Essa firma atua em condições ideais, ou seja, só fabrica os dois produtos, possui um mercado consumidor firme, os preços são fixos, há disponibilidade ilimitada de matéria-prima, as máquinas não quebram e não existe refugo no processo de industrialização.

A demanda semanal pelo produto $P$ corresponde a 100 unidades, ao preço unitário de $R \$ 90$, ao passo que para $Q$ significa 50 peças, ao preço de $R \$ 100$ cada. A firma utiliza as máquinas (recursos de produção) $A, B$, $C$ e $D$ de modo a transformar as matérias-primas MP1, MP2, MP3 e MP4 em produtos acabados. As três primeiras custam $R \$ 20$ cada unidade, enquanto a MP4 custa R\$5. Os fluxos dos processos, os preços, as quantidades e os tempos despendidos na fabricação se encontram esquematizados na figura 3.
Do ponto de vista contábil e da produção, as informações relevantes são listadas abaixo:

- $\quad$ O investimento total empregado pela empresa corresponde a $\mathrm{R} \$ 160 \mathrm{mil}$.

- A empresa tem uma unidade de cada recurso.

- Cada recurso pode ser utilizado durante 8 horas ao dia, nos 5 dias da semana, num total de 2.400 minutos $\left(8^{\prime} 5^{\prime} 60\right)$.

- Os gastos incorridos por semana significam:

(a) mão-de-obra direta: 4 operários, 40 horas semanais, com taxa horária de $R \$ 5$, totalizando $\mathrm{R} \$ 800$ (4'40'5);

(b) custos indiretos de fabricação: pelo total de $R \$ 5.200$.

Ou seja, somando MOD e CIF tem-se como resultado $\mathrm{R} \$ 6$ mil.

- Conforme a figura divulgada (Figura 3), pode-se calcular os tempos de fabricação de ambos os produtos:

(a) $\mathrm{P}=15+10+10+15+5=55$ minutos por cada peça;

(b) $\mathrm{Q}=15+5+5+10+15=50$ minutos por peça.

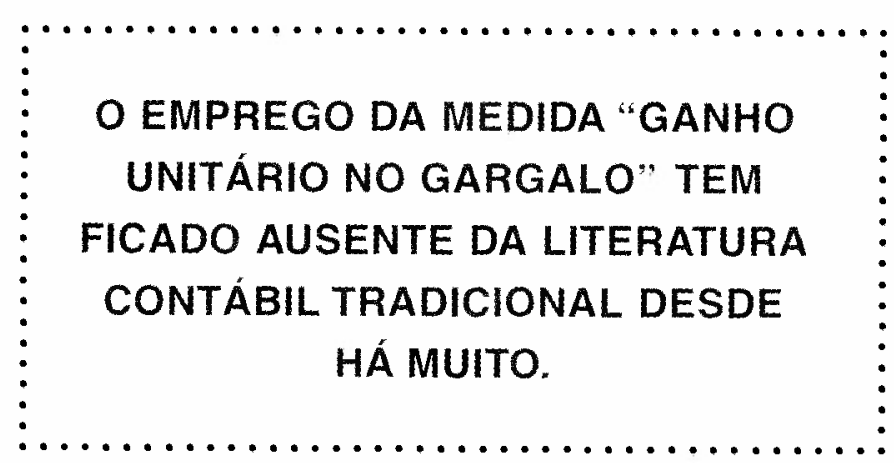

A questão a ser resolvida diz respeito a qual combinação de produtos maximizaria o resultado líquido semanal da empresa.

Pela abordagem convencional (custeio por aḅsorção), seria considerado preferível aquele produto com maior margem bruta. Pelo emprego do custeio direto, aquele que apresentasse a maior margem de contribuição - considerando a MOD como variável. Pela adoção do custeio por atividades, o mix seria composto a partir do produto de maior margem total (receita me-
8. GOLDRATT, E. M., FOX, R. The race. New York: North River Press, 1985. p.98.

9. GOLDRATT, E. M. The Haystack Syndrome: shifting information out of the data ocean. New York: The North River Press, 1990 
nos custo total ponderado pela quantidade de atividades consumidas). Por fim, com base na abordagem TOC, a seleção levaria em conta aquele que mostrasse o maior ganho de acordo com suas restrições inerentes (ganho no gargalo). Nesta última visão, a decisão seria obtida a partir da análise do recurso restritivo de capacidade ( $R R C$ ).

Os cálculos a seguir evidenciam os resultados dos diferentes métodos de custeio, bem como os conflitos envolvidos. Uma vez que o mercado potencial pode absorver 100 unidades do produto $\mathrm{P}$ e 50 unidades de $\mathrm{Q}$, os custos unitários da matéria-prima (MP) e da mão-de-obra direta (MOD) de cada produto seriam obtidos com o auxílio do fluxo de produção exposto. Já o custo indireto de fabricação unitário (CIF) seria obtido pela distribuição dos R\$ 5.200 proporcionalmente ao custo total da MOD para aquelas quantidades de produto. Assim, a margem bruta unitária equivaleria a $R \$ 4,67$ para $P$ e $R \$$ 23,33 para Q. Em decorrência, com base no custeio por absorção, a ênfase recairia sobre o produto $\mathrm{Q}$.

Contudo, a empresa possui determinadas limitações da planta quanto à fabricação desses produtos naquelas quantidades. $\mathrm{Na}$ hipótese daqueles volumes serem manufaturados, a máquina $B$ teria de ser utilizada em horário superior a sua capacidade semanal, ultrapassando as 2.400 horas disponíveis em $25 \%$. As demais máquinas ainda permaneceriam ociosas. Logo, o recurso que restringe a capacidade da fábrica consiste na máquina $\mathrm{B}$.

Figura 3 - Empresa $P \& Q$ recursos produtivos

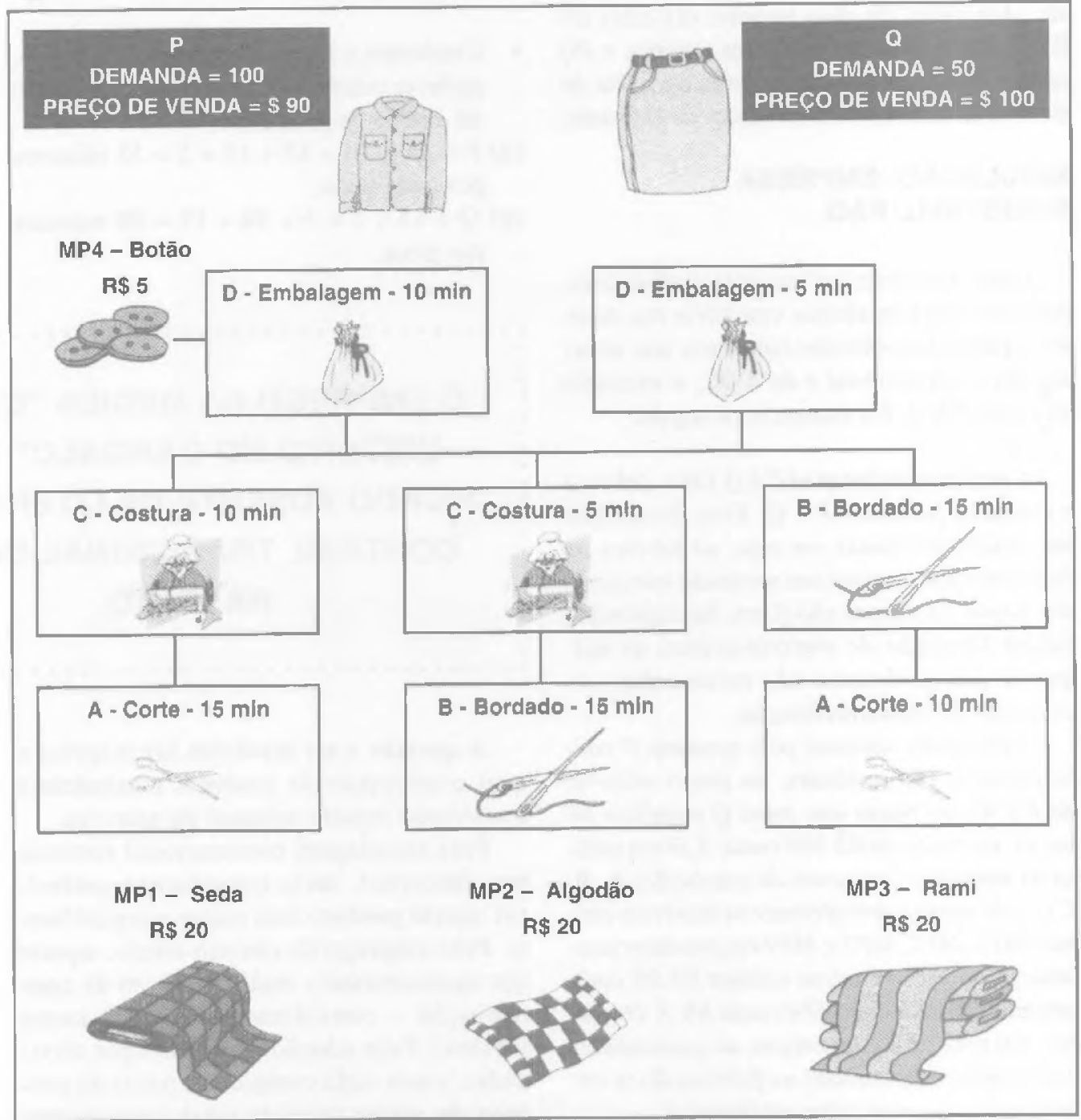


Haja vista essa restrição, a prioridade seria a produção de 50 unidades de $\mathrm{Q}$, o que consumiria 1.500 horas do tempo disponível semanal de B. As 900 horas restantes se destinariam à fabricação de P. Ou seja, a composição "ótima" abrangeria 50 unidades de Q e apenas 60 unidades de P. Tal composição levaria a firma a um prejuízo contábil de $R \$ 300$ por semana.

$\mathrm{O}$ mesmo raciocínio poderia ser aplicado ao custeio direto, que considera, por convenção, a MOD como variável. A margem de contribuição do produto $Q$ também supera aquela obtida para P. Por sua vez, a adoção do sistema $\mathrm{ABC}$ como um aprimoramento ao custeio por absorção, enfatizaria o produto $Q$ da mesma maneira.

Ao contrário, na abordagem da TOC, a decisão seria condicionada ao ganho por unidade de produto no uso do recurso B. Observando-se apenas o montante dos ganhos unitários dos dois produtos (no caso, os res- pectivos preços deduzidos de seus custos totalmente variáveis, a MP), Q seria preferível a $P$ : ganhos de $R \$ 60$ e $R \$ 40$, respectivamente. Não obstante, ao se considerar o RRC neste cálculo, verifica-se que $P$ possui um ganho unitário de RS 3 no gargalo, enquanto Q, somente R\$2. Desse modo, a ênfase recairia sobre a produção de $\mathrm{P}$. $\mathrm{O}$ mix seria composto de 100 unidades de $\mathrm{P}$ e apenas 30 de Q. Essa combinação conduziria a firma a um lucro líquido de $\mathrm{R} \$ 300$.

A despeito de sua simplicidade, o exemplo citado confirma a necessidade de uma maior integração entre as práticas contábeis gerenciais e as medidas de desempenho oriundas da produção. $O$ emprego da medida "ganho unitário no gargalo" tem ficado ausente da literatura contábil tradicional desde há muito.

Serão mostradas a seguir as tabelas de cálculo do exemplo.

\section{TABELAS DE CÁLCULO DO EXEMPLO P\&Q}

a) Abordagem tradicional

Tabela 1 - Demonstração de resultado

\begin{tabular}{|c|c|c|c|c|c|}
\hline \multirow[b]{3}{*}{ Quantidade } & $\mathbf{P}$ & Q & $\mathbf{P}$ & Q & $P+Q$ \\
\hline & \multicolumn{2}{|c|}{ Unitário } & \multicolumn{2}{|l|}{ Total } & Total \\
\hline & & & 100 & 50 & \\
\hline Receita de vendas & 90,00 & 100,00 & 9.000 & 5.000 & 14.000 \\
\hline Custo das vendas & $(85,33)$ & $(76,67)$ & $(8.533)$ & $(3.833)$ & $(12.367)$ \\
\hline Matéria-prima & $(45,00)$ & $(40,00)$ & $(4.500)$ & $(2.000)$ & $(6.500)$ \\
\hline Māo-de-obra direta & $(4,58)$ & $(4,17)$ & $(458)$ & $(208)$ & $(667)$ \\
\hline Custos indiretos fabricação & $(35,75)$ & $(32,50)$ & $(3.575)$ & (1.625) & $(5.200)$ \\
\hline Margem bruta & 4,67 & 23,33 & 467 & 1.167 & 1.633 \\
\hline
\end{tabular}

Tabela 2 - Cálculo de capacidade de fabricação

\begin{tabular}{|c|c|c|c|c|c|c|c|}
\hline & $P(\min )$ & $\times 100$ & $O(\mathrm{~min})$ & $\times 50$ & Total & \multicolumn{2}{|c|}{ / 2.400 Potencial } \\
\hline Recurso A & 15 & 1.500 & 10 & 500 & 2.000 & $83 \%$ & Ocioso \\
\hline Recurso B & 15 & 1.500 & 30 & 1.500 & 3.000 & $125 \%$ & Excesso \\
\hline Recurso C & 15 & 1.500 & 5 & 250 & 1.750 & $73 \%$ & Ocloso \\
\hline Recurso D & 10 & 1.000 & 5 & 250 & 1.250 & $52 \%$ & Ocioso \\
\hline
\end{tabular}

Tabela 3 - Cálculo da utilização do recurso B (restrição)

\begin{tabular}{|l|c|}
\hline Minutos de $B$ para 50 unidades $Q$ & 1.500 \\
\hline Minutos restantes para $P=(2.400-1.500)$ & 900 \\
\hline Quantidade possivel de $P=(900 / 15)$ & 60 \\
\hline
\end{tabular}

\begin{tabular}{|ll|}
\hline \multicolumn{2}{|l|}{ Mix otimizante } \\
\hline$P(u)$ & 60 \\
\hline$Q(u)$ & 50 \\
\hline
\end{tabular}


Tabela 4 - Demonstraçāo gerencial de resultado

\begin{tabular}{|c|c|c|c|}
\hline & R\$/un. & RS/un. & RS Total \\
\hline Receita unitária de vendas & 90 & 100 & \\
\hline Custo unitário da matéria-prima & (45) & $(40)$ & \\
\hline Margem para cobertura CIF e MOD (un.) & 45 & 60 & \\
\hline Unidades fabricadas e vendidas & 60 & 50 & \\
\hline Margem para cobertura CIF e MOD (Tot.) & 2.700 & 3.000 & 5.700 \\
\hline Custo total $=\mathrm{MOD}+\mathrm{CIF}$ & & & $(6.000)$ \\
\hline Prejuizo líquido contábil & & & $(300)$ \\
\hline
\end{tabular}

\section{b) Abordagem da TOC}

Tabela 5 - Demonstração gerencial de resultado

\begin{tabular}{|c|c|c|c|}
\hline & $P$ (R\$/un.) & $Q(\mathrm{R} \$$ /un.) & RS Total \\
\hline Receita unltárla de vendas & 90 & 100 & \\
\hline Custo totalmente variável = MP & (45) & $(40)$ & \\
\hline Ganho unitário & 45 & 60 & \\
\hline Classificação estratégica & $2^{\circ}$ & 10 & \\
\hline Tempo usado no RRC = Fator B & 15 & 30 & \\
\hline Ganho por minuto no RRC & 3,00 & 2,00 & \\
\hline Nova classılficação de prlorldade & 12 & $2^{2}$ & \\
\hline Tempo efetivo usado pelo RRC & 1500 & 900 & \\
\hline Mix otimizante pela TOC (un.) & 100 & 30 & \\
\hline Ganho total & 4.500 & 1.800 & 6.300 \\
\hline Despesas operacionais = CIF + MOD & & & $(6.000)$ \\
\hline Lucro líquido contábil & & & 300 \\
\hline
\end{tabular}

\section{CONCLUSŌES E RECOMENDAÇŌES}

Nos anos recentes, o sistema econômico se tornou mais competitivo e o ambiente de manufatura, mais informatizado e automatizado. A globalização dos mercados nacionais conduziu as empresas uma elevação de seus níveis de produtividade a fim de sobreviverem. Todavia, as inovaçōes introduzidas no chão de fábrica não foram acompanhadas por avanços significativos nas técnicas utilizadas pela Contabilidade Gerencial e de Custos: a ênfase persistia no controle dos custos.

$O A B C$ significou a primeira grande alteração de enfoque, mas, ainda assim, apresentava distorções quanto a seu processo decisório, haja vista derivar da abordagem convencional: incentivava a concentração da produção em poucas linhas de produtos (linhas de produtos emergentes, mas de alto consumo de atividades não eram incentivadas) e não considerava as restrições inerentes ao processo de fabricação.

Pouco depois, a abordagem TOC iniciou sua difusão. Esta visão procurou estabelecer uma ligação mais estrita entre Contabilidade e Produção ao associar os registros contábeis e decisões gerenciais aos "gargalos" existentes nas linhas de fabricação e/ou no mercado (restriçốes físicas). Ainda muito recente, esta abordagem tenderá a expandir-se nos próximos anos, haja vista a ausência de estudos empíricos e experimentais em algumas de suas áreas de conhecimento. Nesse sentido, a presente pesquisa visou a acrescentar parte dessas novas idéias que começam a se desenvolver no país. 